\title{
Relation of Retinopathy of Prematurity to Brain Volumes at Term Equivalent Age and Developmental Outcome at 2 Years of Corrected Age in Very Preterm Infants
}

\author{
Kristbjörg Sveinsdóttir $^{\mathrm{a}}$ David Ley $^{\mathrm{a}}$ Holger Hövel $^{\mathrm{b}}$ Vineta Fellman $^{\mathrm{a}, \mathrm{c}}$ \\ Petra S. Hüppi $^{d}$ Lois E.H. Smith ${ }^{e}$ Ann Hellström ${ }^{f}$ Ingrid Hansen Pupp ${ }^{a}$ \\ aDivision of Pediatrics, Department of Clinical Sciences, Skåne University Hospital, Lund University, Lund, Sweden; \\ ${ }^{b}$ Division of Pediatrics, Department of Clinical Sciences, Central Hospital Kristianstad, Lund, Sweden; ' $C$ Children's \\ Hospital, University of Helsinki, Helsinki, Finland; ${ }^{d}$ Division of Development and Growth, Department of Pediatrics, \\ University Hospital of Geneva, Geneva, Switzerland; 'Department of Opthalmology, Boston Children's Hospital,

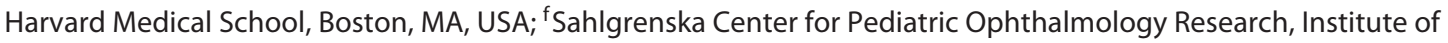 \\ Neuroscience and Physiology, University of Gothenburg, Gothenburg, Sweden
}

\section{Keywords}

Brain volume - Developmental outcome - Magnetic resonance imaging - Mental developmental index · Psychomotor developmental index · Preterm birth . Retinopathy of prematurity

\footnotetext{
Abstract

Background: Retinopathy of prematurity (ROP) is a major complication of preterm birth and has been associated with later visual and nonvisual impairments. Objectives: To evaluate relationships between any stage of ROP, brain volumes, and developmental outcomes. Methods: This study included 52 very preterm infants (gestational age [mean \pm SD]: 26.4 \pm 1.9 weeks). Total brain, gray matter, unmyelinated white matter (UWMV), and cerebellar volumes were estimated in 51 out of 52 infants by magnetic resonance imaging at termequivalent age. Bayley Scales of Infant Development were used to assess developmental outcomes in 49 out of 52 in-
}

fants at a mean corrected age of 24.6 months. Results: Nineteen out of 52 infants developed any stage of ROP. Infants with ROP had a lower median (IQR) UWMV (173 [156-181] vs. 204 [186-216] $\mathrm{mL}, p<0.001)$ and cerebellar volume (18.3 [16.5-20] vs. 22.3 [20.3-24.7] $\mathrm{mL}, p<0.001)$ than infants without ROP. They also had a lower median (IQR) mental developmental index (72 [56-83] vs. 100 [88-104], $p<0.001$ ) and a lower psychomotor developmental index (80 [60-85] vs. 92 [81-103], $p=0.002$ ). Brain volumes and developmental outcomes did not differ among infants with different stages of ROP. Conclusion: Any stage of ROP in preterm infants was associated with a reduced brain volume and an impaired developmental outcome. These results suggest that common pathways may lead to impaired neural and neurovascular development in the brain and retina and that all stages of ROP may be considered in future studies on ROP and development. (c) 2018 S. Karger AG, Basel

\section{KARGER}

(c) 2018 S. Karger AG, Basel

E-Mail karger@karger.com

www.karger.com/neo
Kristbjörg Sveinsdóttir, MD

Division of Pediatrics, Department of Clinical Sciences

Lund University Hospital

SE-221 85 Lund (Sweden)

E-Mail kristbjorg.sveinsdottir@med.lu.se 


\section{Introduction}

With the increasing survival of extremely preterm infants, a proportionately greater number of infants are affected by major complications of prematurity, where neurodevelopmental disability and visual problems are among the most common $[1,2]$. Preterm birth coincides with a critical period of brain development but also with that of vascular development [3].

The retina is incompletely developed at preterm birth. Retinopathy of prematurity (ROP) is considered to be a consequence of a primary arrest of retinal vascularization and a neurovascular disease involving both vascular and neural components $[4,5]$. Postnatal head growth retardation can be regarded as a proxy of brain growth and coincides with suppression of retinal vascular growth and with low levels of IGF-1, an important vascular and neural growth factor [6]. These events can be further related to the development of severe ROP and low brain volumes at term-equivalent age $[6,7]$.

Preterm infants who develop severe ROP appear to be at an increased risk for visual [2] and nonvisual neurodevelopmental comorbidities and delayed white matter maturation as estimated by magnetic resonance imaging (MRI) at an early postnatal age and at term-equivalent age [8-11]. These findings suggest the presence of common mechanisms in the development of these complications [6].

Although ROP is defined according to different stages, the disease is a continuous process of impaired vascular and neuronal retinal development. Therefore, our aim in this study was to evaluate the relationship between the presence of any stage of ROP, brain growth, and later developmental outcomes at 2 years of corrected age.

\section{Materials and Methods}

\section{Study Population}

The original prospective study included 64 very preterm infants born in the neonatal intensive care unit (Lund, Sweden) between January 2005 and May 2007, where IGF-1 concentrations from birth until term age in relation to growth, MRI-estimated brain volume, and developmental outcome were evaluated [7, 12, 13]. Fifty-two infants completed the study until term age, 51 out of 52 underwent MRI at term age, and 49 out of 52 received a follow-up examination at 2 years of corrected age. Inclusion criteria were: gestational age $<31$ weeks, absence of major congenital anomalies, and written informed parental consent. Of the 64 recruited infants, 9 did not survive until term age and the parents of 3 infants chose to leave the study.

This study was approved by the regional ethical review board of Lund, Sweden, and adhered to the tenets of the Declaration of Helsinki. All pregnancies were dated by ultrasound at $17-18$ weeks of gestation.

ROP, Brain Volume, and Outcome

\section{Clinical Dato}

The weight standard deviation score at birth was calculated from a Scandinavian intrauterine growth curve based on fetal weights estimated by ultrasound [14]. Cumulative doses $(\mathrm{mg} / \mathrm{kg})$ of administered hydrocortisone and betamethasone were registered until postmenstrual age (PMA) 35 weeks. Total steroid exposure was estimated by converting the betamethasone dosage into hydrocortisone equivalents (1:40). Bronchopulmonary dysplasia was defined as a requirement for supplemental oxygen at PMA 36 weeks. Septicemia was defined as the presence of a positive blood culture and concomitant increased levels of C-reactive protein.

\section{Nutritional Regime and Calculation of Intake}

The nutritional strategy used for the infants has been described previously [7] and was based on individualized enteral nutrition using maternal or donor breast milk (fortified if required) and additional parenteral nutrition, initiated as soon as possible after birth. Maternal and donor breast milk were analyzed weekly for protein and energy contents, and enteral and parenteral daily intakes of protein $(\mathrm{g} / \mathrm{kg} /$ day) and energy (kcal/ $\mathrm{kg} /$ day) were prospectively calculated from birth until at least PMA 35 weeks.

\section{Cerebral Ultrasound}

Cerebral ultrasounds were performed on days 1,3 , and 7 , at 3 and 6 weeks of age, and at term. Severe intracranial hemorrhage was defined as the presence of IVH grade III or parenchymal hemorrhage. White matter damage was defined as the presence of periventricular echodensities or cysts that persisted for $>7$ days. Severe brain damage was defined as severe intracranial hemorrhage and/ or white matter damage.

\section{ROP Examination}

ROP screening followed the Swedish national protocol and began at 5-6 weeks of age, but not before PMA 31 weeks. The infants underwent retinal examinations through dilated pupils biweekly to once weekly depending on ROP severity until either the retina was fully vascularized or the condition was considered stable. ROP was classified according to the International Classification of Retinopathy of Prematurity [15], and treatment followed the recommendations of the Early Treatment for Retinopathy of Prematurity Cooperative Group [16].

\section{Magnetic Resonance Imaging}

MRI was performed on a 3-T Siemens Magnetom Allegra head scanner (Siemens AG Medical Solutions, Erlangen, Germany) in 51 out of 52 infants at term age (mean \pm SD: $40.1 \pm 0.6$ gestational weeks). The protocol for image acquisition and image processing has previously been described in detail [7]. We calculated the total brain volume (TBV), gray matter volume (GMV), and unmyelinated white matter volume (UWMV) in 46 infants and the cerebellar volume in 51 infants.

\section{Assessment at 2 Years of Corrected Age}

A psychologist assessed developmental outcomes in 49 out of 52 infants at a mean $( \pm S D)$ corrected age of $24.6( \pm 0.8)$ months by means of the Bayley Scales of Infant Development (BSID-II) with 2 different index scales, i.e., the MDI and the PDI, as previously described [13]. 
Table 1. Clinical characteristics according to the presence of retinopathy of prematurity

\begin{tabular}{|c|c|c|c|}
\hline & No ROP $(n=33)$ & $\operatorname{ROP}(n=19)$ & $p$ value \\
\hline Gestational age, weeks & $27.4(24.3$ to 30.6$)$ & $25.0(23.0$ to 27.1$)$ & $<0.001$ \\
\hline Birth weight, $g$ & $970(592$ to 1,716$)$ & $634(348$ to 854$)$ & $<0.001$ \\
\hline SDS weight at birth & $-0.7(-4.4$ to 0.8$)$ & $-1.8(-4.7$ to 0.6$)$ & 0.1 \\
\hline Apgar score $<7$ at $5 \mathrm{~min}$ & $11(33)$ & $10(53)$ & 0.172 \\
\hline Male/female ratio & $15 / 18(45 \% / 55 \%)$ & $10 / 9(53 \% / 47 \%)$ & 0.62 \\
\hline Severe brain damage ${ }^{a}$ & $2(6)$ & $3(16)$ & 0.342 \\
\hline Septicemia & $7(21)$ & $12(63)$ & 0.002 \\
\hline Total steroid intake ${ }^{\mathrm{b}}, \mathrm{mg} / \mathrm{kg}$ & $0(0$ to 112$)$ & $34(0$ to 105$)$ & $<0.001$ \\
\hline Bronchopulmonary dysplasia & $22(67)$ & $16(84)$ & 0.206 \\
\hline Energy intake ${ }^{\mathrm{c}}, \mathrm{kcal} / \mathrm{kg} /$ day & $120(104$ to 140$)$ & $121(93$ to 134$)$ & 0.653 \\
\hline Protein intake ${ }^{c}, g / k g /$ day & $3.2(2.6$ to 3.7$)$ & $3.0(2.6$ to 3.6$)$ & 0.082 \\
\hline
\end{tabular}

Values are presented as medians (range) or numbers (\%). The total number of patients was 52. SDS, standard deviation score. ${ }^{\text {a }}$ Intraventricular hemorrhage grade III, parenchymal hemorrhage, and/or white matter damage as defined by a cerebral ultrasound. ${ }^{\mathrm{b}}$ Calculated hydrocortisone equivalents from birth until postmenstrual age 35 weeks. ${ }^{\mathrm{c}}$ From birth until postmenstrual age 35 weeks.

\section{Statistical Analysis}

Statistical analysis was performed with SPSS 23 for Microsoft Windows (IBM, Armonk, NY, USA). $p<0.05$ was considered statistically significant. Univariate analyses of differences between groups were assessed with the Mann-Whitney $U$ test or the $\chi^{2}$ test as appropriate. Correlations between continuous variables were evaluated with the Spearman rank correlation coefficient.

Adjustment for other variables was performed with multiple linear regression analysis. In all models GA, birth weight (BW), and gender were included as independent variables. Additionally, all variables exhibiting significant univariate associations with the respective outcome variables (Table 2 ) were entered into the multivariate model as independent variables. Thus, independent variables entered into the analysis for cerebellar volume and UWMV, respectively, were: GA (days), BW, gender, septicemia, and total steroid intake (hydrocortisone equivalents in $\mathrm{mg} / \mathrm{kg}$ ) from birth until PMA 35 weeks. The independent variables entered into the analysis for MDI were: GA, BW, gender, Apgar score $<7$ at 5 min, and total steroid intake from birth until PMA 35 weeks. The independent variables entered into the analysis for PDI were: GA (days), BW, gender, and severe brain damage.

\section{Results}

\section{Clinical Characteristics and Development of ROP}

Table 1 presents the clinical characteristics of infants with and without ROP. Infants with any ROP $(n=19)$ had a lower GA, a lower BW, a higher frequency of septicemia, and a higher total steroid intake compared to infants without ROP.

\section{Clinical Characteristics in Relation to Cerebellar Volume, UWMV, MDI, and PDI}

Table 2 presents relationships between clinical characteristics and cerebellar volume, UWMV, MDI, and PDI, respectively. GA correlated with cerebellar volume $\left(r_{\mathrm{s}}=\right.$ $0.56, p<0.001)$, UWMV $\left(r_{\mathrm{s}}=0.71, p<0.001\right)$, and both $\operatorname{MDI}\left(r_{\mathrm{s}}=0.46, p=0.001\right)$ and PDI $\left(r_{\mathrm{s}}=0.34, p=0.015\right)$. BW correlated with cerebellar volume $\left(r_{\mathrm{s}}=0.71, p<\right.$ $0.001)$, UWMV $\left(r_{\mathrm{s}}=0.82, p<0.001\right)$, and MDI $\left(r_{\mathrm{s}}=0.41\right.$, $p=0.004)$. Apgar score $<7$ at $5 \mathrm{~min}$ was associated with a lower MDI ( $p=0.047)$, and severe brain damage was associated with a lower PDI $(p=0.025)$. Any septicemia was associated with cerebellar volume $(p=0.022)$ and UWMV $(p=0.021)$. A higher total steroid intake correlated with a lower cerebellar volume $\left(r_{\mathrm{s}}=-0.45, p=0.001\right)$, UWMV $\left(r_{\mathrm{s}}=-0.50, p<0.001\right)$, and MDI $\left(r_{\mathrm{s}}=-0.39, p=0.006\right)$.

\section{Stages of ROP in Relation to Brain Volume and Neurodevelopmental Outcome}

Out of 52 infants, 33 had no ROP, 9 had ROP stage 1 or 2 , and 10 had ROP stage 3 ( 9 of these 10 infants received laser treatment). None of the infants had ROP $>$ stage 3 .

Infants with ROP stage 1 or 2 had a lower mean TBV, GMV, UWMV, cerebellar volume, MDI, and PDI compared to infants without ROP $(p=0.001, p=0.007, p<$ $0.001, p<0.001, p=0.008$, and $p=0.024$, respectively). Infants with treated ROP had lower TBV, UWMV, cerebellar volume, and $\mathrm{MDI}(p=0.03, p=0.002, p=0.005$, and $p=$ 0.002 ), whereas no significant difference could be shown for GMV or PDI, as compared to infants without ROP.
Sveinsdóttir/Ley/Hövel/Fellman/Hüppi/ Smith/Hellström/Hansen Pupp 
Table 2. Relationships between clinical characteristics and cerebellar volume and unmyelinated white matter volume at a postmenstrual age of 40 weeks and MDI and PDI at 2 years of corrected age

\begin{tabular}{|c|c|c|c|c|}
\hline & $\begin{array}{l}\text { Cerebellar } \\
\text { volume } \\
p \text { value }\end{array}$ & $\begin{array}{l}\text { Unmyelinated white } \\
\text { matter volume } \\
p \text { value }\end{array}$ & $\begin{array}{l}\text { MDI } \\
p \text { value }\end{array}$ & $\begin{array}{l}\text { PDI } \\
p \text { value }\end{array}$ \\
\hline Gestational age (days) & $<0.001$ & $<0.001$ & 0.001 & 0.015 \\
\hline Birth weight $(\mathrm{g})$ & $<0.001$ & $<0.001$ & 0.004 & 0.191 \\
\hline Apgar score $<7$ at $5 \mathrm{~min}$ & 0.992 & 0.78 & 0.047 & 0.344 \\
\hline Male/female ratio & 0.178 & 0.379 & 0.312 & 0.13 \\
\hline Severe brain damage ${ }^{a}$ & 0.298 & 0.9 & 0.111 & 0.025 \\
\hline Septicemia & 0.022 & 0.021 & 0.199 & 0.294 \\
\hline Total steroid intake ${ }^{\mathrm{b}}(\mathrm{mg} / \mathrm{kg})$ & 0.001 & $<0.001$ & 0.006 & 0.079 \\
\hline Bronchopulmonary dysplasia & 0.063 & 0.076 & 0.362 & 0.656 \\
\hline Energy intake $^{\mathrm{c}}$ (kcal/kg/day) & 0.72 & 0.723 & 0.961 & 0.787 \\
\hline Protein intake $^{\mathrm{c}}(\mathrm{g} / \mathrm{kg} /$ day $)$ & 0.138 & 0.907 & 0.496 & 0.957 \\
\hline Maternal educational level ${ }^{\mathrm{d}}$ & - & - & 0.099 & 0.352 \\
\hline Paternal educational level ${ }^{\mathrm{d}}$ & - & - & 0.131 & 0.223 \\
\hline
\end{tabular}

The total number of patients was 52. MDI, Mental Developmental Index; PDI, Psychomotor Developmental Index. ${ }^{a}$ Intraventricular hemorrhage grade III, periventricular hemorrhagic infarction, and/or white matter disease as defined by a cerebral ultrasound. ${ }^{b}$ Calculated hydrocortisone equivalents from birth until postmenstrual age 35 weeks. ${ }^{\mathrm{c}}$ From birth until postmenstrual age 35 weeks. ${ }^{\mathrm{d}}$ University degree vs. no university degree.

Table 3. Brain volumes at a postmenstrual age of 40 weeks and Mental Developmental Index and Psychomotor Developmental Index at 2 years of corrected age in infants with any ROP or no ROP

\begin{tabular}{lccr}
\hline & Any ROP & No ROP & $p$ value \\
\hline Total brain volume, $\mathrm{mL}$ & $371(329-390)$ & $416(377-445)$ & $<0.001$ \\
Gray matter volume, $\mathrm{mL}$ & $193(161-201)$ & $204(186-231)$ & 0.054 \\
Unmyelinated white matter volume, $\mathrm{mL}$ & $173(156-181)$ & $204(186-216)$ & $<0.001$ \\
Cerebellar volume, mL & $18.3(16.5-20)$ & $22.3(20.3-24.7)$ & $<0.001$ \\
Mental Developmental Index & $72(56-83)$ & $100(88-104)$ & $<0.001$ \\
Psychomotor Developmental Index & $80(60-85)$ & $92(81-103)$ & 0.002 \\
\hline
\end{tabular}

Values are presented as medians (IQR). ROP, retiniopathy of prematurity. ${ }^{\mathrm{a}} n=19 .{ }^{\mathrm{b}} n=32$.

The mean values of brain volumes and developmental outcomes did not differ between infants with ROP (stages 1-3) and those with treated ROP.

\section{Any ROP in Relation to Brain Volumes and}

Developmental Outcome

Table 3 presents the median (IQR) values of brain volumes (TBV, GMV, UWMV, and cerebellar volume) and developmental outcomes (MDI and PDI) in infants with and without ROP. In univariate analysis infants with any ROP had significantly lower TBV, UWMV, cerebellar volumes, MDI, and PDI than infants without ROP.
Multiple linear regression analysis was performed in order to further evaluate the relationship between any ROP and brain volumes at term-equivalent age and neurodevelopmental outcome at 2 years of age. After adjustment for GA the relationships between any ROP and TBV and GMV, respectively, did not remain significant and were not further evaluated in multivariate models. Figure $1 \mathrm{a}-\mathrm{c}$ shows the relationships between any ROP and cerebellar volume, UWMV, MDI, and PDI, respectively.

Table 4 presents the contribution of any ROP to cerebellar volume, UWMV, MDI, and PDI following multivariate regression analysis. The relationships between any ROP and cerebellar and UWMV, respectively, re- 


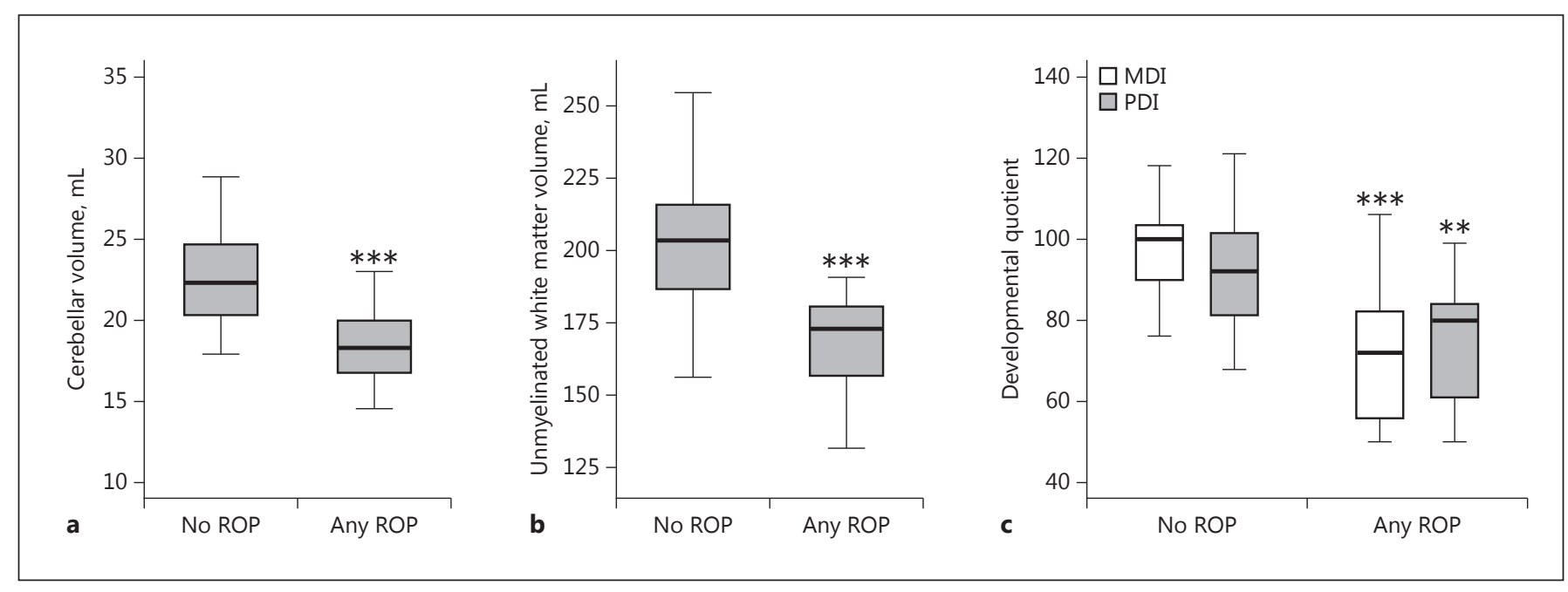

Fig. 1. Median and IQR of cerebellar volume (a), unmyelinated white matter volume (b), and Mental Developmental Index (MDI) and Psychomotor Developmental Index (PDI) (c) in relation to the presence or absence of retinopathy of prematurity $(\mathrm{ROP}) .{ }^{* *} p \leq 0.01 ;{ }^{* * *} p \leq 0.001$.

Table 4. Contribution of any ROP to cerebellar volume and to UWMV at a postmenstrual age of 40 weeks and to MDI and PDI at 2 years of corrected age in a linear regression model

\begin{tabular}{llll}
\hline Outcome variable & $p$ value & \multicolumn{2}{l}{ Any ROP (yes/no) } \\
\cline { 3 - 4 } & & $R^{2}$ & adjusted $R^{2}$ \\
\hline Cerebellar volume $^{\mathrm{a}}$ & 0.029 & 0.50 & 0.43 \\
UWMV $^{\mathrm{a}}$ & 0.030 & 0.58 & 0.52 \\
MDI $^{\mathrm{b}}$ & 0.007 & 0.38 & 0.29 \\
PDI $^{\mathrm{c}}$ & 0.03 & 0.42 & 0.35 \\
\hline
\end{tabular}

ROP, retinopathy of prematurity; UWMV, unmyelinated white matter volume; MDI, Mental Developmental Index; PDI, Psychomotor Developmental Index. ${ }^{\text {a }}$ Included independent variables: any ROP (yes/no), gestational age (days), birth weight (g), gender, septicemia (yes/no), and total steroid intake (calculated hydrocortisone equivalents in $\mathrm{mg} / \mathrm{kg}$ ) from birth to a postmenstrual age of 35 weeks. ${ }^{\text {b }}$ Included independent variables: any ROP (yes/no), gestational age (days), birth weight (g), gender, Apgar score $<7$ at $5 \mathrm{~min}$, and total steroid intake (calculated hydrocortisone equivalents in $\mathrm{mg} / \mathrm{kg}$ ) from birth to a postmenstrual age of 35

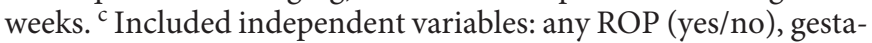
tional age (days), birth weight (g), gender, and severe brain damage (IVH grade III, and/or parenchymal hemorrhage, and/or WMD).

mained significant after adjustment for GA, BW, gender, septicemia, and total steroid intake. The relationship between any ROP and MDI remained significant after adjustment for GA, BW, gender, Apgar score $<7$ at $5 \mathrm{~min}$, and total steroid intake. The relationship between any ROP and PDI remained significant after adjustment for GA, BW, gender, and severe brain damage.

\section{Discussion}

Our main findings were that the presence of any stage of ROP was associated with a lower cerebellar volume and UWMV at term-equivalent age and with impaired cognitive and motor development at 2 years of corrected age. Thus, infants with less severe ROP (stage 1 or 2 ) exhibited a degree of brain volume reduction and neurodevelopmental impairment similar to that of infants with more severe ROP (stage 3 ).

Several studies have shown an association between ROP and impaired later developmental outcomes [2, 9-11]. The majority of studies compare severe ROP to no ROP and do not include less severe stages of ROP. A recent case-control study comparing severe ROP with no or stage 1 ROP found severe ROP to be associated with reduced cerebellar and brainstem volumes at term and with neurodevelopmental deficits at 15 months and 2 years of age [17]. One study considered different stages of ROP and found the severity of neonatal ROP to be a marker for functional disability at 5.5 years of age. They found high rates of disability in VLBW infants who develop severe ROP and subsequently have unfavorable visual outcomes [18]. 
Several features of retinal and brain development have links to common pathways that in turn may be affected by insults associated with very preterm birth. This is supported by similar risk factors being associated with ROP, lower brain volumes, and impaired neurodevelopment, which suggests common antecedent events that affect migration and proliferation in both the retina and the brain. The signaling and mitogenic protein and transcription factor sonic hedgehog is a key factor in both cerebellar and retinal proliferation during early development $[19$, 20].

In this study, ROP was primarily associated with a lower cerebellar volume and UWMV. These respective brain regions and the retina may present a common vulnerability due to depletion of the same trophic factors. IGF-1 is an anabolic hormone that is critical to both vascular and neural development. Low IGF-1 levels in preterm infants have been associated with ROP [21], decreased brain volumes, and impaired neurodevelopmental outcomes at 2 years of corrected age $[7,13]$.

The relationship between ROP and poor white matter development as determined by diffusion tensor imaging and tractography has been evaluated in one study where severe ROP predicted a white matter maturational delay in the optic radiations but also in other regions of posterior white matter. The delayed white matter maturation was present independently of other signs of brain injury [11]. The retinal nerve fiber layer as estimated by spectraldomain optical coherence tomography at term-equivalent age is thinner in very preterm infants and has been shown to correlate with white matter injury at term-equivalent age and later impaired neurodevelopment [22].

The presence of supratentorial brain injury has previously been associated with impaired cerebellar growth [23]. The presence of severe brain damage, as defined by cerebral ultrasound, was not related to any ROP or to the estimated cerebellar volume in the current study although the small number of infants with severe brain damage could have obscured such an association.

In addition to a lower cerebellar volume and UWMV, infants with any ROP had significantly lower MDI and PDI scores at 2 years of corrected age. Stage 1 ROP is sometimes difficult to diagnose and subtle forms may be missed at examination. However, similar findings were reported in another study, in which the stage of ROP per se did not determine the subsequent presence of neurodevelopmental impairment [9]. Several studies have also documented the importance of cerebellar volume, particularly with respect to cognitive function in preterm infants at 2 years of age [13, 24, 25].
The accumulated dose of steroid intake displayed a significant association with any ROP, lower cerebellar and UWMV, and lower MDI. Postnatal corticosteroid exposure in preterm infants has previously been related to an increased risk of ROP, an altered optic radiation structure, and impaired cerebellar growth [26-28]. The neonatal cerebellum has the highest number of glucocorticoid receptors [29]. In mice, glucocorticoids inhibit proliferation of cerebellar granular neuron precursors [30].

In conclusion, we found that the development of any stage of ROP in very preterm infants was associated with reduced brain volumes and impaired developmental outcomes at 2 years of corrected age. Though based on a small cohort of infants, our results suggests that any type of ROP, not just severe, should be considered in future studies on ROP and developmental outcomes. These findings also raise the possibility of common pathways essential for the development of the retina and brain. Therefore, strategies aimed at preventing any stage of ROP may also have neuroprotective effects on the developing brain.

\section{Acknowledgement}

We thank all of the families who participated in this study and the study nurses Eva Hammarstrand and Ann-Cathrine Berg for their excellent assistance.

\section{Disclosure Statement}

Insulin-like growth factor 1 is covered by the patent owned by or licensed to Premacure AB, Uppsala, Sweden. A.H., D.L., and I.H.P. own shares in the company with a financial interest in Premacure AB. A.H., D.L., L.E.H.S., and I.H.P. work as consultants for Shire Pharmaceuticals (Lexington, MA, USA).

\section{Funding Sources}

This work was supported by the Swedish Medical Research Council (2014-3140), European Commission FP7 project 305485 PREVENT-ROP, ALF government grants to Lund University, VINNOVA, the Skåne Council Foundation for Research and Development, the Linnéa and Josef Carlsson Foundation for Research and Development, and NIH EY024864, EY017017, P01 HD18655, and the Lowy Medical Research Institute. 


\section{References}

1 Laptook AR, O’Shea TM, Shankaran S, Bhaskar B; NICHD Neonatal Network: Adverse neurodevelopmental outcomes among extremely low birth weight infants with a normal head ultrasound: prevalence and antecedents. Pediatrics 2005;115:673-680.

-2 Hellgren KM, Tornqvist K, Jakobsson PG, Lundgren P, Carlsson B, Källén K, Serenius F, Hellström A, Holmström G: Ophthalmologic outcome of extremely preterm infants at 6.5 years of age: Extremely Preterm Infants in Sweden Study (EXPRESS). JAMA Ophthalmol 2016, DOI: 10.1001/2016.0391.

$\checkmark 3$ Volpe JJ: Cerebellum of the premature infant: rapidly developing, vulnerable, clinically important. J Child Neurol 2009;24:1085-1104.

4 Chen J, Smith LE: Retinopathy of prematurity. Angiogenesis 2007;10:133-140.

$\checkmark 5$ Hellström A, Smith LE, Dammann O: Retinopathy of prematurity. Lancet 2013;26: 1445-1457.

-6 Löfqvist C, Engström E, Sigurdsson J, Hård AL, Niklasson A, Ewald U, Holmström G, Smith LE, Hellström A: Postnatal head growth deficit among premature infants parallels retinopathy of prematurity and insulinlike growth factor-1 deficit. Pediatrics 2006; 117:1930-1938.

$>7$ Hansen-Pupp I, Hövel H, Hellström A, Hellström-Westas L, Löfqvist C, Larsson EM, Lazeyras F, Fellman V, Hüppi PS, Ley D: Postnatal decrease in circulating insulin-like growth factor-I and low brain volumes in very preterm infants. J Clin Endocrinol Metab 2011;96:1129-1135.

$>8$ Allred EN, Capone A Jr, Fraioli A, Dammann O, Droste P, Duker J, Gise R, Kuban K, Leviton A, O'Shea TM, Paneth N, Petersen R, Trese M, Stoessel K, Vanderveen D, Wallace DK, Weaver G: Retinopathy of prematurity and brain damage in the very preterm newborn. J AAPOS 2014;18:241-247.

$\checkmark 9$ Beligere N, Perumalswamy V, Tandon M, Mittal A, Floora J, Vijayakumar B, Miller MT: Retinopathy of prematurity and neurodevelopmental disabilities in premature infants. Semin Fetal Neonatal Med 2015;20:346-353.

10 Schmidt B, Davis PG, Asztalos EV, Solimano A, Roberts R: Association between severe retinopathy of prematurity and nonvisual disabilities at age 5 years. JAMA 2014;311:523525.

11 Glass TJA, Chau V, Gardiner J, Foong J, Vinall J, Zwicker JG, Grunau RE, Synnes A, Poskitt KJ, Miller SP: Severe retinopathy of prematurity predicts delayed white matter maturation and poorer neurodevelopment. Arch Dis Child Fetal Neonatal Ed 2017; 102:F532-F537.
12 Hansen-Pupp I, Löfqvist C, Polberger S, Niklasson A, Fellman V, Hellström A, Ley D: Influence of insulin-like growth factor I and nutrition during phases of postnatal growth in very preterm infants. Pediatr Res 2011;69: 448-453.

13 Hansen-Pupp I, Hövel H, Lofqvist C, Hellström-Westas L, Cilio CM, Andersson S, Fellman V, Ley D: Circulatory insulin-like growth factor-I and brain volumes in relation to neurodevelopmental outcome in very preterm infants. Pediatr Res 2013;74:564-569.

14 Marsal K, Persson PH, Larsen T, Lilja H, Selbing A, Sultan B: Intrauterine growth curves based on ultrasonically estimated foetal weights. Acta Paediatr 1996;85:843-848.

15 International committee for the Classification of Retinopathy of Prematurity: The International Classification of Retinopathy of Prematurity revisited. Arch Ophthalmol 2005;123:991-999.

16 Early Treatment for Retinopathy of Prematurity Cooperative Group: Revised indications for the treatment of retinopathy of prematurity: results of the early treatment for retinopathy of prematurity randomized trial. Arch Ophthalmol 2003;121:1684-1694.

17 Drost FJ, Keunen K, Moeskops P, Claessens N, van Kalken F, Isgum I, Voskuil-Kerkhof E, Groenendaal F, de Vries LS, Benders MJ, Termote J: Severe retinopathy of prematurity is associated with reduced cerebellar and brainstem volumes at term and neurodevelopmental deficits at 2 years. Pediatr Res 2018, Epub ahead of print.

18 Msall ME, Phelps DL, DiGaudio KM, Dobson V, Tung B, McClead RE, Quinn GE, Reynolds JD, Hardy RJ, Palmer EA: Severity of neonatal retinopathy of prematurity is predictive of neurodevelopmental functional outcome at age 5.5 years. Behalf of the Cryotherapy for Retinopathy of Prematurity Cooperative Group. Pediatrics 2000;106:998-1005.

19 Haldipur P, Bharti U, Govindan S, Sarkar C, Iyengar S, Gressens P, Mani S: Expression of sonic hedgehog during cell proliferation in the human cerebellum. Stem Cells Dev 2012; 21:1059-1068.

20 Wang Y, Dakubo G, Thurig S, Mazerolle CJ, Wallace VA: Retinal ganglion cell-derived sonic hedgehog locally controls proliferation and the timing of RGC development in the embryonic mouse retina. Development 2005; 132:5103-5113.
21 Jensen AK, Ying GS, Huang J, Quinn GE, Binenbaum G: Postnatal serum insulin-like growth factor I and retinopathy of prematurity. Retina 2017;37:867-872.

22 Rothman AL, Sevilla MB, Mangalesh S, Gustafsson KE, Edwards L, Cotten CM, Shimony JS, Pizoli CE, El-Dairi MA, Freedman SF, Toth CA: Thinner retinal nerve fiber layer in very preterm versus term infants and relationship to brain anatomy and neurodevelopment. Am J Ophthalmol 2015;160:12961308.

23 Tam EW, Miller SP, Studholme C, Chau V, Glidden D, Poskitt KJ, Ferriero DM, Barkovich AJ: Differential effects of intraventricular hemorrhage and white matter injury on preterm cerebellar growth. J Pediatr 2011;158: 366-371.

24 Lind A, Parkkola R, Lehtonen L, Munck P, Maunu J, Lapinleimu H, Haataja L; PIPARI Study Group: Associations between regional brain volumes at term-equivalent age and development at 2 years of age in preterm children. Pediatr Radiol 2011;41:953-961.

25 Van Kooij BJ, Benders MJ, Anbeek P, Van Haastert IC, De Vries LS, Groenendaal F: Cerebellar volume and proton magnetic resonance spectroscopy at term, and neurodevelopment at 2 years of age in preterm infants. Dev Med Child Neurol 2012;54:260-266.

26 Movsas TZ, Spitzer A, Gewolb IH: Postnatal corticosteroids and risk of retinopathy of prematurity. J AAPOS 2016;20:348-352.

27 Kelly CE, Cheong JL, Molloy C, Anderson PJ, Lee KJ, Burnett AC, Connelly A, Doyle LW, Thompson DK; Victorian Infant Collaborative Study Group: Neural correlates of impaired vision in adolescents born extremely preterm and/or extremely low birthweight. PLoS One 2014;9:e93188.

28 Tam EW, Chau V, Ferriero DM, Barkovich AJ, Poskitt KJ, Studholme C, Fok ED, Grunau RE, Glidden DV, Miller SP: Preterm cerebellar growth impairment after postnatal exposure to glucocorticoids. Sci Transl Med 2011; 3:105ra105.

29 Pavlik A, Buresova M: The neonatal cerebellum: the highest level of glucocorticoid receptors in the brain. Brain Res 1984;314:13-20.

30 Heine VM, Rowitch DH: Hedgehog signaling has a protective effect in glucocorticoid-induced mouse neonatal brain injury through an 11betaHSD2-dependent mechanism. J Clin Invest 2009;119:267-277. 